\title{
Diffusion and Access to Scientific and Technological Data in the Regulatory Framework of Innovation Public Funds in Chile
}

\author{
Difusión y Acceso a Datos e Información Científica y Tecnológica en la \\ Normativa de Fondos Públicos para la Innovación en Chile
}

\author{
Paulina Sanhueza', Ignacio Rodríguez², Patricio Padilla ${ }^{3}$
}

\begin{abstract}
This paper analyzes the regulatory framework in the public funds of the National Innovation System in Chile regarding diffusion and access to scientific and technological data. The results show several failures in the innovation regulatory framework. Concerning data diffusion, most funds do not clearly define who should carry out the diffusion activities, do not promote sufficiently the diffusion of non-confidential information and show little interest in defining and planning diffusion activities. Regarding data sharing, it should be clearly specified the means in which $R+D+i$ data and process are to be delivered. In addition, open access requirements to researchers present serious deficiencies, while compliance of commitments, although show better results, should further improve.

El artículo analiza el marco normativo, en materia de difusión y acceso a datos e información científica y tecnológica, de los fondos públicos enmarcados en el Sistema Nacional de Innovación chileno. Los resultados muestran la existencia de carencias en la normativa. En materia de difusión de información, la mayoría de los fondos no definen al responsable de llevar a cabo dichas actividades, no resguardan significativamente el derecho a difundir la información no confidencial, y dejan la definición y planificación de actividades de difusión como temas pendientes. Por su parte, en el intercambio de datos, la definición del soporte y/o formato de los productos y procesos resultantes de las actividades de I+D+i presenta espacios para la mejora de resultados. Asimismo, las condiciones de acceso a la información a otros investigadores muestra serias carencias, mientras que los incentivos al cumplimiento de los compromisos contraídos, a pesar de mostrar mejores resultados, deberían presentar un mayor esfuerzo normativo.
\end{abstract}

Keywords: data sharing; regulatory framework; national innovation system; scientific and technological data. intercambio de datos; marco normativo; sistema nacional de innovación; datos e información científica y tecnológica.

'Departamento de Administración y Economía, Universidad de La Frontera, Avenida Francisco Salazar 0I I45, Temuco, Chile.

56-45 73402I, psanhue@ufro.cl

2Departamento de Ciencias Sociales, Centro de Investigaciones Sociológicas (CIS), Universidad de La Frontera, Avenida Francisco Salazar 0I I45,Temuco, Chile, 56-45-734069, irodriguez@ufro.cl

${ }^{3}$ Instituto de Desarrollo Local y Regional (IDER), Universidad de La Frontera, Avenida Francisco Salazar 0 I I45, Temuco, Chile.

56-45-3259I I, ppadilla@ufro.cl

ISSN: 07 I8-2724. (http://www.jotmi.org)

Journal of Technology Management \& Innovation (C) Universidad Alberto Hurtado, Facultad de Economía y Negocios. 


\section{Introducción}

Las ventajas para la ciencia y la innovación de disponer de datos e información accesible para todos los investigadores son evidentes. Muchos científicos del pasado, que no han vivido en esta época digital caracterizada por el desarrollo de las Tecnologías de la Información y la Comunicación (TIC), podrían considerar este fenómeno como una utopía. En la actualidad, sin embargo, la Revolución Tecnológica ha posibilitado que este ideal se convierta en realidad.

El interés en el libre acceso a datos de información científica y tecnológica para la comunidad científica es, por tanto, bastante reciente. Sin embargo, el debate que se ha abierto en relación a esta temática y la reflexión en torno a los potenciales beneficios que tiene para la ciencia y para el fortalecimiento de la capacidad innovadora, ha hecho que algunas disciplinas hayan comenzado a desarrollar iniciativas prometedoras en este campo. También los países comienzan a reaccionar para adaptar las instituciones y las políticas públicas a las nuevas demandas de los científicos e investigadores, entendiendo que los rendimientos crecientes y el aprovechamiento de externalidades que puede generar un buen marco institucional y normativo en esta materia es una oportunidad que no pueden dejar pasar.

No obstante, los estudios realizados a nivel mundial sobre las políticas de gestión de información y acceso a datos de carácter científico y tecnológico, han comenzado desde hace poco a cobrar importancia pero éstos son aún muy escasos. En Chile, notoriamente constituye todavía una tarea pendiente. Esta investigación pretende sentar las bases para un diagnóstico en mayor profundidad de la estructura de incentivos que tienen los investigadores para compartir información. Sin desconocer que existen varios aspectos que contribuyen al desarrollo y fortalecimiento de iniciativas que apunten en esta dirección, en este trabajo se centra la discusión en la identificación de las carencias normativas presentes en los fondos públicos para la innovación enmarcados en el Sistema Nacional de Innovación (SNI) en Chile.

Este trabajo es una síntesis de un estudio más amplio realizado por los autores en el proyecto "Estado del arte nacional e internacional en materia de gestión de datos de investigación e información científica y tecnológica y recomendaciones de buenas prácticas". Fondo concursable de CONICYT. Ficha Licitación N N I 57 I-I I I06LP08. Comisión Nacional de Investigación Científica y Tecnológica (CONICYT). Ejecutor: Instituto de Desarrollo Local y Regional (IDER). Universidad de La Frontera.

\section{Marco Teórico}

2.I. La gestión de datos de investigación e información científica

Los datos de investigación se definen como registros de hechos (resultados numéricos, textos, imágenes y sonidos) utilizados como fuentes primarias para la investigación científica. Estos son comúnmente aceptados en la comunidad científica por permitir la validación de resultados en la investigación científica, mientras que la información científica se refiere a las conclusiones obtenidas del análisis de datos y a los resultados de una investigación (IDER, 20I0). La OCDE ha desarrollado directrices internacionales que orientan y regulan el acceso a datos de investigación e información científica generados con fondos públicos por investigadores e instituciones científico-tecnológicas (Pilat y Fukasaku, 2007). Estos principios pretenden constituirse en estándares internacionales que permitan orientar el diseño de políticas de gestión en el patrimonio de datos de investigación e información científica en los distintos países.

El carácter patrimonial de los datos de investigación e información científica se adquiere al ser éstos generados con ayuda total o parcial de fondos públicos, es decir, emanados desde el Estado mediante sus políticas e instrumentos para la investigación y desarrollo desde cualquier nivel de gobierno. La naturaleza del conocimiento, en el que concurren las propiedades de no exclusión y no rivalidad, sugieren que nos encontramos ante lo que los economistas denominan un bien público. Conviene señalar que la designación de bien público no se refiere a que sea el sector público quien suministra el bien, sino a su naturaleza técnica. El principio de no exclusión establece que cuando un bien se suministra para un individuo, simultáneamente se suministra, sin posibilidad de exclusión, para toda la sociedad. Para entender adecuadamente este principio conviene indicar que, al contrario de lo que sucede con los bienes públicos, los bienes privados siguen el principio de exclusión, puesto que se pueden establecer mecanismos, generalmente la compra del bien en cuestión a través del pago del precio del producto, para acceder a dicho bien. Por otra parte, los bienes públicos cumplen el principio de no rivalidad, puesto que el consumo que realiza un individuo del bien no impide que a su vez lo consuman otros individuos. Es decir, una vez que se genera un bien público, éste puede ser utilizado simultáneamente por distintos individuos sin necesidad de volver a inventarse de nuevo. En consecuencia, el costo de producir un bien público sólo se paga una vez y los beneficios recaen sobre todos los miembros de la sociedad, por lo que los mercados privados no tienen incentivos para producir este tipo de bienes, a no ser que puedan apropiarse de los rendimientos de su esfuerzo para suministrarlos a la sociedad a través de derechos de propiedad intelectual e industrial, o alguna for-

ISSN: 07 I8-2724. (http://www.jotmi.org)

Journal of Technology Management \& Innovation (C) Universidad Alberto Hurtado, Facultad de Economía y Negocios. 
ma que garantice que sigan el principio de exclusión.Aunque parezca extraño, en el mundo abundan los bienes públicos. Para nuestro propósito en esta investigación, nos interesa destacar que las ideas y el conocimiento son bienes públicos. Insistimos en señalar que lo normal es que los mercados privados produzcan una cantidad insuficiente de este tipo de bienes. Esta situación constituye un fallo del mercado que justifica la intervención pública para alcanzar un nivel de provisión eficiente de este tipo de bienes a la sociedad. El desarrollo de políticas de gestión a nivel internacional se caracteriza por la existencia de fuertes restricciones técnicas e institucionales en el acceso a datos de investigación e información científica (Den Besten, David, Schroeder, 2010). Por tanto surge, en primer lugar, la necesidad de desarrollar políticas que fomenten el acceso abierto y la colaboración científica identificando problemas para cada área científica en la gestión de datos e información (Rodríguez, 2008; San José Montano, 2009). Además de ello se refuerza la necesidad de generar un proceso de sensibilización, es decir, dar a conocer e institucionalizar la problemática en todos los actores involucrados (Sabourin y Dumouchel, 2007).

En segundo lugar, se hace necesario la creación de organismos que resguarden los datos de algún área científica determinada y el desarrollo de inventarios de los activos de información del sector público (Ramos, Mendo, Arquero, 2009) y procedimientos de estandarización de información (Eito, 2007), todos ellos entendidos por la OCDE como criterios de interoperabilidad (Pilat y Fukasaku, 2007). Por lo general éstos se alimentan de los resultados emanados de proyectos e investigaciones generadas con fondos públicos que son puestos a disposición de la comunidad científica.

En tercer lugar, se reconoce que los fondos que permiten el apoyo, o la total realización de proyectos científicos, deberían incluir dentro de sus aspectos normativos no sólo lo relacionado con los objetivos globales de carácter estrictamente científico, sino además lo concerniente al tratamiento y accesibilidad a bases de datos e información más relacionadas con procesos que con resultados.

2.2. La importancia del marco regulatorio como instrumento que facilite la generación de ciencia, tecnología e innovación

La diseminación del conocimiento constituye un pilar básico de un entorno innovador (Vázquez Barquero, 1999, 2005), por lo que el Estado juega un importante rol en fomentar la difusión de datos de investigación e información científica generados a través de fondos de investigación públicos.

Consideramos necesario que se asigne a priori, en el momento de la licitación de un fondo público, la responsabilidad sobre la difusión de información asociada a la investigación, puesto que al ser un proceso costoso puede surgir desin- terés para llevar a cabo estas actividades una vez que ya se han recibido los recursos. Para evitar que se produzca esa falta de incentivos post-contractual es preciso, por tanto, que la responsabilidad de difusión venga especificada formalmente, lo que la convierte inmediatamente en exigible. En ocasiones la responsabilidad conjunta de las actividades de difusión, si bien garantiza un compromiso por las partes, puede degenerar en falta de obligaciones de ninguna de ellas si se produce en un entorno de incertidumbre. Por ello, es primordial que las actividades se encuentren cabalmente definidas y planificadas. Insistimos en señalar que el compromiso formal en la licitación funciona como incentivo al cumplimiento de estas actividades. Finalmente, consideramos importante que el organismo público se asegure el derecho a difundir libremente la información no confidencial. En la hipotética eventualidad que las actividades de difusión no sean realizadas por la parte beneficiaria del fondo, una cláusula de este tipo constituye una salvaguarda para poder divulgar la información y potencialmente aprovechar externalidades de red que, de otra forma, podrían perderse.

Por otra parte, la revista científica Nature señalaba recientemente que "en la actualidad cada vez más el éxito de un proyecto de investigación viene medido no sólo por las publicaciones que produce, sino también por los datos que pone a disposición de la comunidad científica" (Nature, 2009, p. 145), y advertía que la investigación no puede surgir si los datos e información científica no se preservan y se vuelven accesibles. En este sentido, destacan algunas iniciativas en campos como la física, la astronomía, las matemáticas, la geofísica, la biodiversidad, la ecología y la biología molecular. Algunos ejemplos exitosos son los repositorios "arXiv.org", "International Council for Science's World Data System", "Protein Data Bank", "GenBank”, "International Virtual Observatory Alliance", "PANGAEA", etc. (Nelson, 2009). Algunos países han reconocido la importancia de este aspecto para el futuro de la investigación y han creado centros como el "Digital Curation Centre" radicado en la Universidad de Edimburgo, o instituido programas como el "US National Science's Foundation's DataNet Programme" (Nature, 2009). En este sentido, cobra relevancia el incorporar procesos de la actividad científica, entendidos como bases de datos y el levantamiento de información, ya que éstos son vitales para el avance de iniciativas posteriores (Uhlir y Schröder, 2007; Xu, 2007; Schmal,Acuña, Klein, 20I I).

Sin embargo, a pesar de estas iniciativas aisladas y de los potenciales beneficios de compartir información entre investigadores, las políticas de apoyo a la innovación y a la promoción del conocimiento no han hecho del libre acceso a la información compartida su prioridad. Esta situación es preciso que cambie y para ello las instituciones que otorgan fondos a la investigación, las universidades, los investigadores $y$ en general, todos aquellos que realizan este tipo de activi- 
dades tienen que tomar conciencia y contribuir al desarrollo de marcos técnicos, culturales e institucionales en los que se promueva el libre acceso a datos de información científica y tecnológica.

Huelga decir que no todos los datos e información son susceptibles de ser públicos ya que podrían existir datos que, por su naturaleza, atenten contra la confidencialidad, la seguridad alimentaria o la seguridad nacional en caso de que fuesen compartidos. En estas situaciones la literatura señala que la normativa debe ser transparente, flexible y ordenada para salvaguardar estos aspectos y así otorgar al patrimonio de datos e información algún tipo de diseminación que sea beneficioso y útil. Por ejemplo, un caso típico donde esta situación ocurre es en el tratamiento de los datos epidemiológicos del "National Center for Health Statistics" en Estados Unidos. Debido a lo delicado de la información manipulada, se conformó un "seguro de investigación", llamado RDC, en el cual el almacenamiento de información respondía a determinados criterios y el ingreso únicamente se permitía bajo una estricta supervisión. Así, la única forma de acceder al RDC era mediante una propuesta de los investigadores que permitía aceptarlos y hacer uso de este material. Ejemplos de restricción del RDC son la configuración especial de los puertos USB y todo tipo de mecanismos de transferencia de datos que lo hacen inaccesible. Las estaciones de trabajo se han configurado de tal manera que los usuarios reciben acceso de "sólo lectura" a los datos y archivos solicitados, y pueden escribir sólo en la estación de trabajo local del disco duro. Estas restricciones garantizan que los usuarios no puedan eliminar información que no ha sido sometida a una revisión de confidencialidad. En este sentido, la información de difícil gestión, con características que la hacen diferentes y merecedoras de protocolos especiales, debe ser identificada en las áreas científicas, establecer los motivos de resguardo y generar el tipo de restricciones y condiciones de acceso para su uso (Abowd y Lane, 2004; Schröder, 2007; Bachrach y Spittel, 20I I).

En general, los científicos encuentran numerosos argumentos teóricos para apoyar proyectos en los que se comparte la información, pero en la práctica muchos eligen no hacerlo por la incertidumbre sobre los derechos que tienen que transferir, el riesgo de que se usen los datos de forma incorrecta o el tiempo que tienen que dedicar a la actividad (Nelson, 2009). Por un lado, se precisa que los investigadores guarden sus archivos en formatos que sean compatibles con motores de búsqueda que faciliten la trazabilidad de la información, y por otro, que la normativa de los fondos condicione la concesión de recursos a que los investigadores envíen los archivos a centros de datos en los que éstos se compartan.

Por su importancia, en esta investigación también se han considerado estos aspectos sobre los incentivos al libre acceso a datos de información científica y tecnológica como una categoría de análisis del estudio. Consideramos que las agencias públicas que otorgan fondos a investigadores deberían incentivarlos a compartir datos con otros investigadores para aprovechar las externalidades y rendimientos crecientes asociados a esta práctica. El compromiso de los organismos públicos con la promoción del libre acceso a datos de información científica y tecnológica, entendemos que se puede estructurar a partir de un diseño normativo que contemple este tipo de actividades en el otorgamiento de recursos a los investigadores.

\section{Aspectos metodológicos}

3.I. Definición del alcance, diseño y unidad de análisis de la investigación

La presente investigación se basa en un estudio de caso, cuyo alcance es del tipo exploratorio/descriptivo. Se examina el Sistema Nacional de Innovación chileno, concretamente el marco normativo de los fondos públicos enmarcados en el mismo, en materia de difusión y acceso a datos e información científica y tecnológica, problemática poco abordada por estudios precedentes, especificando sus principales características. En cuanto al diseño del estudio, se ha planteado como uno del tipo no experimental transversal o transeccional. La investigación tiene como unidad de análisis el Sistema Nacional de Innovación chileno, tomando como población de estudio dentro del mismo a los principales programas de las instituciones que otorgan fondos para actividades de $\mathrm{I}+\mathrm{D}+\mathrm{i}$ (GRÁFICO I).

La muestra del tipo no probabilística considera a aquellos programas del SNI cuyas bases de licitación de su última convocatoria pública estuviesen publicadas a inicios del año 2010 en el sitio web de la institución otorgante. La composición de la muestra analizada por institución otorgante (GRÁFICO 2) y la participación de los programas analizados sobre el total de la muestra (GRÁFICO 3) se presentan a continuación.

\subsection{Técnica de análisis y definición de variables}

En la investigación se aplica la técnica de análisis de contenido cuantitativo. A partir de ella y de acuerdo a lo desarrollado previamente en el marco teórico, se ha considerado pertinente realizar un análisis que contemple las siguientes categorías: difusión de la información e intercambio de datos. A su vez, cada categoría se ha evaluado de acuerdo a diversas características dentro de los programas abordados en el presente estudio (TABLA I). Una vez codificada la información, se ha aplicado el análisis de distribución de frecuencias. 


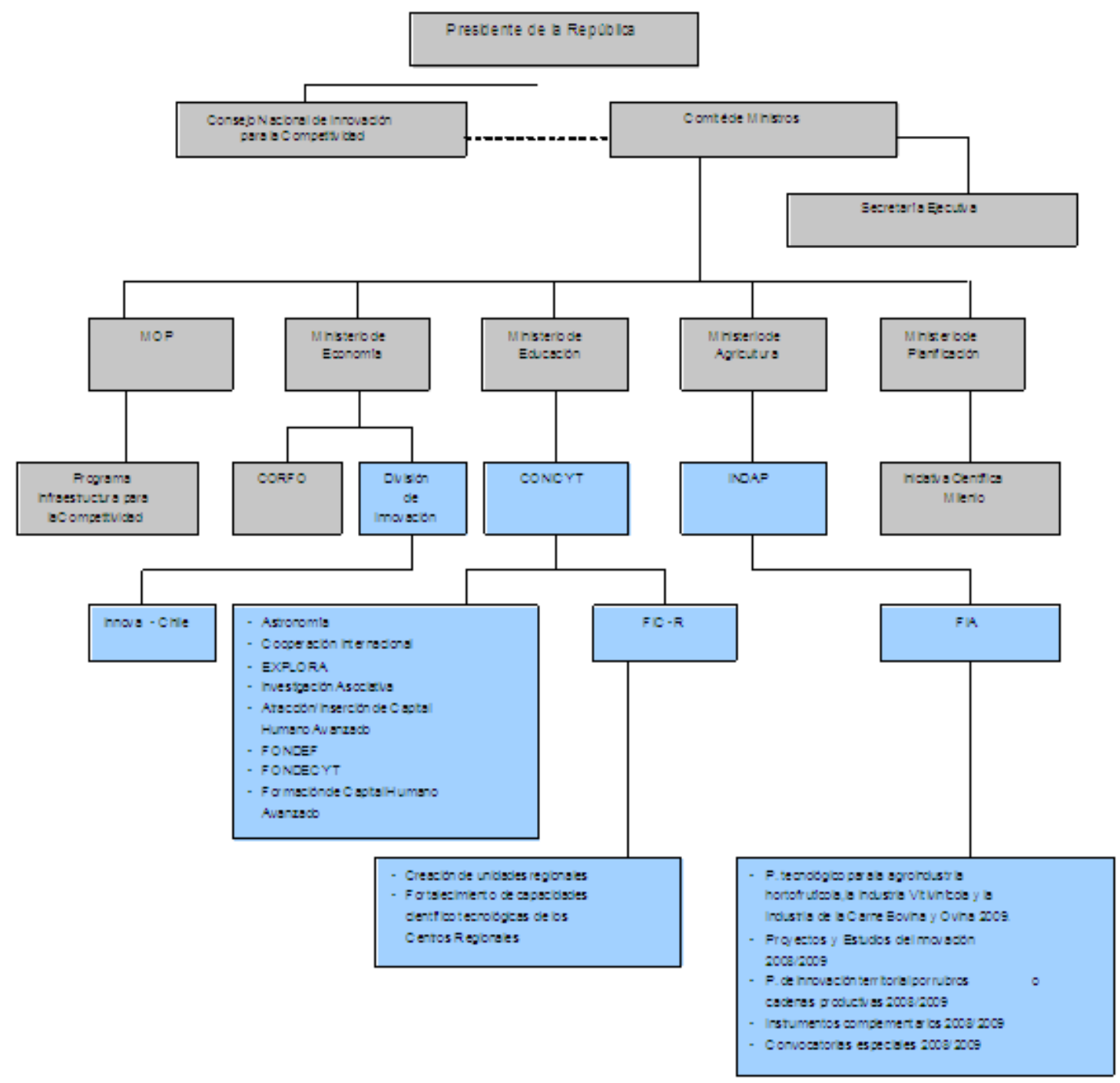

GRÁFICO I Fondos y programas que componen la muestra

Nota: Los fondos y programas que componen la muestra aparecen señalados en azul. Fuente: Elaboración propia.

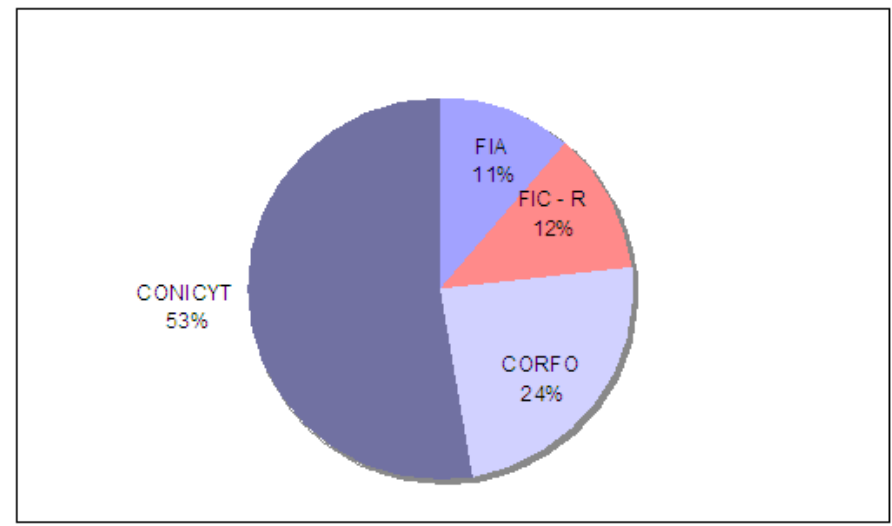

GRÁFICO 2 Composición de la muestra analizada por institución Fuente: Elaboración propia 


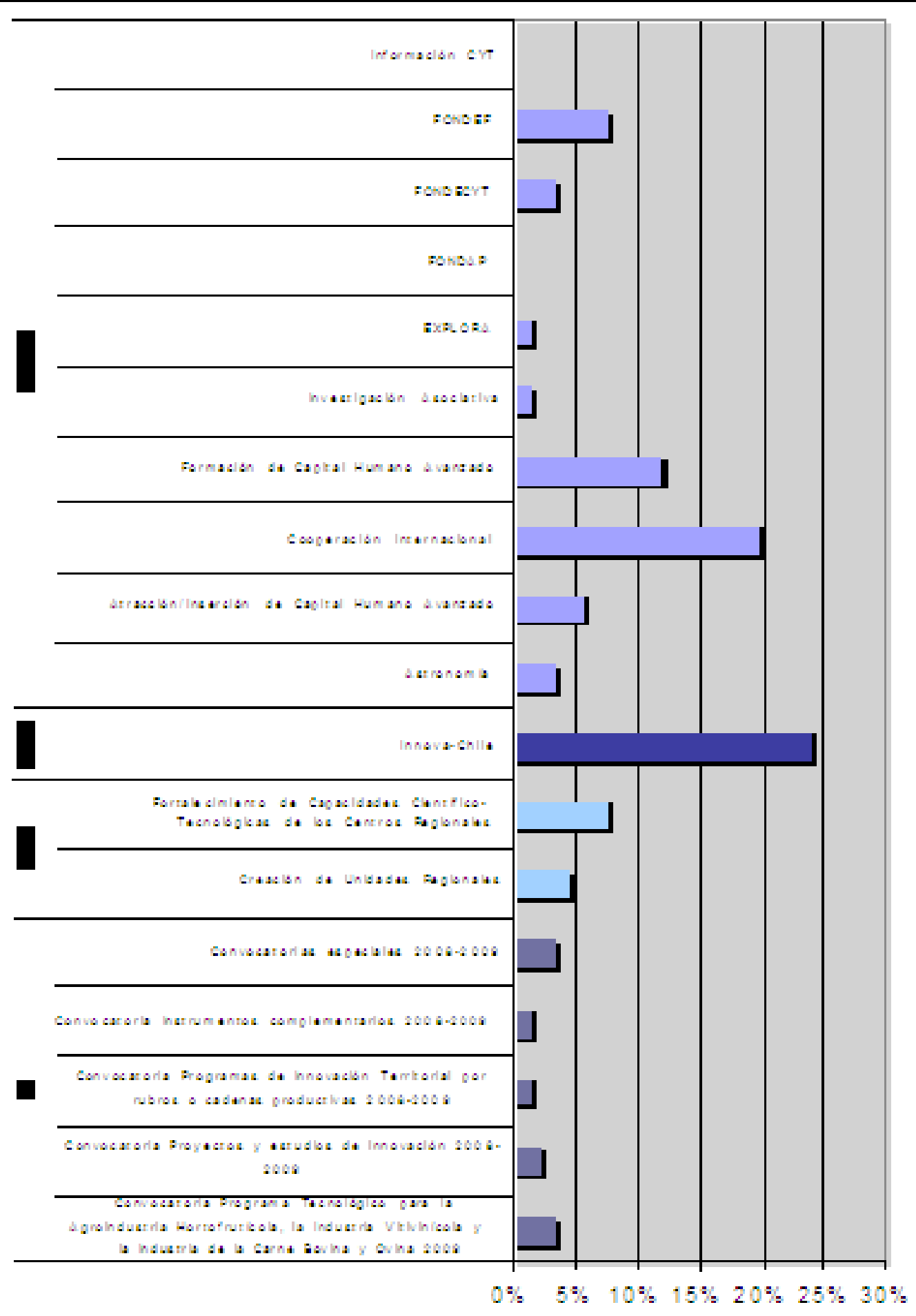

GRÁFICO 3 Participación de los programas analizados en el total de la muestra. Fuente: Elaboración propia 
En relación a los "Aspectos a evaluados" conviene aclarar la distinción que se realiza entre "producto" y "proceso". Entendemos por "producto" los resultados finales de la utilización de los fondos otorgados: informes, tesis, inventos, etc. Por otra parte, el "proceso" constituye los procedimientos, datos, información, metodologías, bases de datos, etc. generados, obtenidos y/o recopilados durante la implementación de los programas que conducen y sirven de soporte a la obtención de los resultados finales, es decir, al producto. Adicionalmente, en "Resultados" se ha denominado como "n.d" a todos aquellos aspectos que no han podido ser identificados en las bases de licitación de los fondos, bien porque no se encuentran especificados o porque no procede tal categoría para el programa analizado. Un análisis con mayor detalle, que aborde esta distinción, podría ser motivo de una nueva investigación.

\section{Marco Empírico}

4.I. Resultados del análisis en materia de difusión de la información

En el análisis realizado se ha atendido a los obstaculizadores y facilitadores normativos que articulan el esfuerzo de di- fusión de la información. En concreto, se han identificado los siguientes aspectos: (i) ¿sobre quién recae la responsabilidad de difusión de la información?, (ii) ¿se permite la libre difusión de la información no confidencial? y, (iii) ise definen y planifican las actividades de difusión de información? Estas preguntas pretenden dar cuenta de la exigibilidad formal que los organismos públicos pueden establecer en las licitaciones a los recursos, con los que se financian actividades de innovación, para de esta forma garantizar el cumplimiento de la actividad de difusión de la información.

Los resultados de la información analizada indican que la mayoría de los fondos públicos del Sistema Nacional de Innovación no definen quién es el responsable de llevar a cabo las actividades de difusión (GRÁFICO 4). Tan sólo CONICYT reconoce en un grado significativo a la beneficiaria como responsable de esta actividad. En los fondos FIC-R este aspecto se encuentra totalmente ausente, mientras que en el resto de fondos el porcentaje de definición de la responsabilidad no supera el $10 \%$ y se establece una responsabilidad conjunta. Es importante hacer énfasis en lo señalado anteriormente acerca de este tipo de responsabilidades conjuntas, puesto que si bien garantiza un compromiso por las partes, éste puede diluirse entre ellas en entornos de incertidumbre. Recomendamos definir quién tiene la respon-

\begin{tabular}{|c|c|c|c|}
\hline Categorías & Aspectos evaluados & Preguntas & Resultados \\
\hline \multirow{3}{*}{$\begin{array}{l}\text { Difusión de la } \\
\text { información }\end{array}$} & Responsable & $\begin{array}{l}\text { ¿Quién es el responsable de la } \\
\text { actividad de difusión? }\end{array}$ & $\begin{array}{l}\text { - Institución otorgante } \\
\text { - Beneficiaria } \\
\text { - Propiedad conjunta } \\
\text { - n.d: No disponible }\end{array}$ \\
\hline & Información no confidencial & $\begin{array}{l}\text { ¿Existe una cláusula que permita } \\
\text { la libre difusión de información no } \\
\text { confidencial? }\end{array}$ & $\begin{array}{l}\text { - } \mathrm{Si} \\
\text { - } \mathrm{No}\end{array}$ \\
\hline & Planificación & $\begin{array}{l}\text { ¿Existe una cláusula que } \\
\text { planifique las actividades de } \\
\text { difusión? }\end{array}$ & $\begin{array}{l}\text { - } \mathrm{Si} \\
\text { - } \mathrm{No}\end{array}$ \\
\hline \multirow{3}{*}{$\begin{array}{l}\text { Intercambio de } \\
\text { Datos }\end{array}$} & $\begin{array}{l}\text { Soporte/formato de } \\
\text { entrega de información }\end{array}$ & $\begin{array}{l}\text { Producto/Proceso: ¿Existe una } \\
\text { cláusula que defina el soporte/ } \\
\text { formato de entrega de la infor- } \\
\text { mación? }\end{array}$ & $\begin{array}{l}\cdot \text { Si } \\
\text { - No }\end{array}$ \\
\hline & Acceso a la información & $\begin{array}{l}\text { Producto/Proceso: ¿Existe una } \\
\text { cláusula en la que se disponga } \\
\text { que la información es de libre ac- } \\
\text { ceso para otros investigadores? }\end{array}$ & $\begin{array}{l}\text { - } \mathrm{Si} \\
\text { - } \mathrm{No}\end{array}$ \\
\hline & $\begin{array}{l}\text { Cumplimiento de entrega } \\
\text { de la información }\end{array}$ & $\begin{array}{l}\text { ¿Existe una cláusula en la } \\
\text { que se resguarde/incentive el } \\
\text { cumplimiento de los compromisos } \\
\text { de entrega de la información? }\end{array}$ & $\begin{array}{l}\text { - } \mathrm{Si} \\
\text { - No }\end{array}$ \\
\hline
\end{tabular}

TABLA I Categorías y aspectos evaluados Fuente: Elaboración propia

ISSN: 07 I8-2724. (http://www.jotmi.org)

Journal of Technology Management \& Innovation @ Universidad Alberto Hurtado, Facultad de Economía y Negocios. 


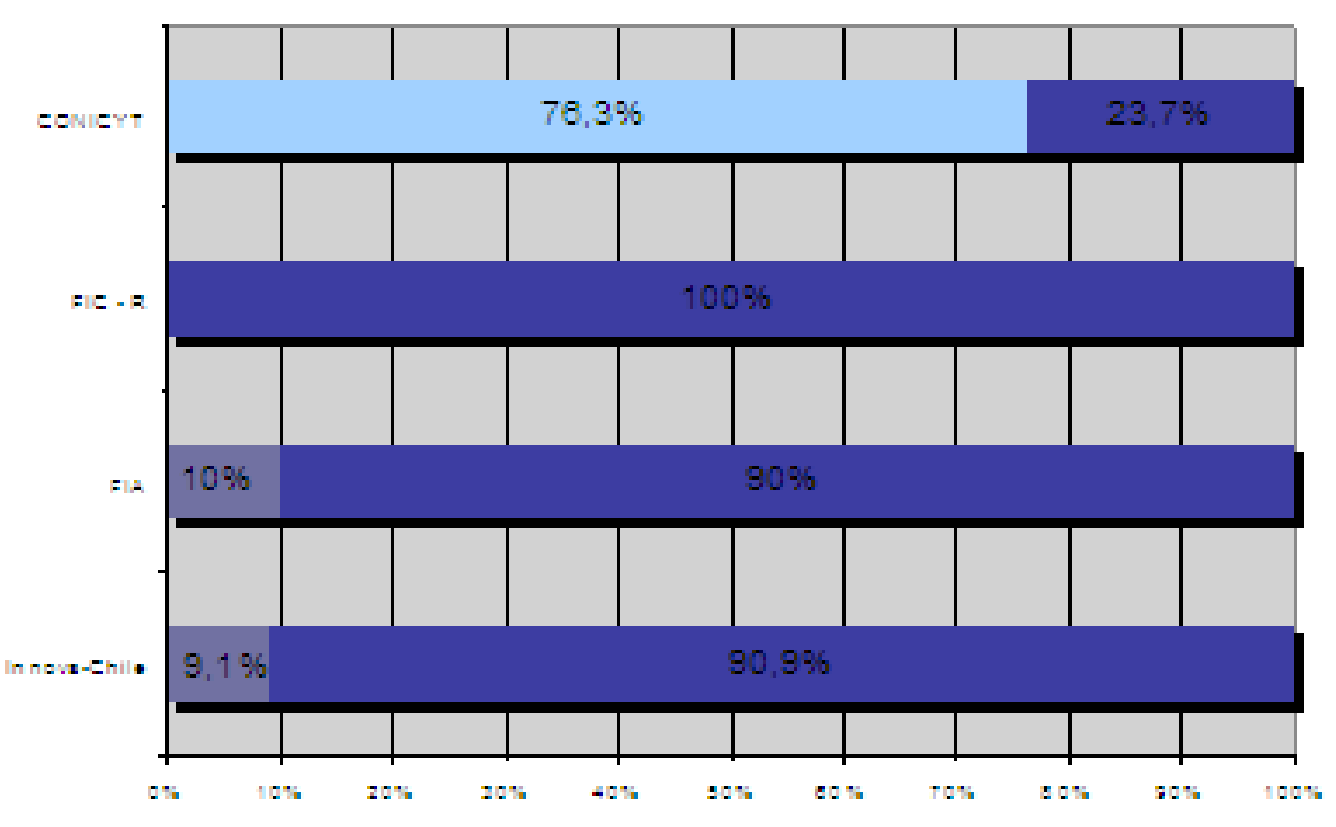

Institución otorgante Beneficiaria $\quad$ Propiedad conjunta

GRÁFICO 4 Definición de la responsabilidad de las actividades de difusión. Fuente: Elaboración propia

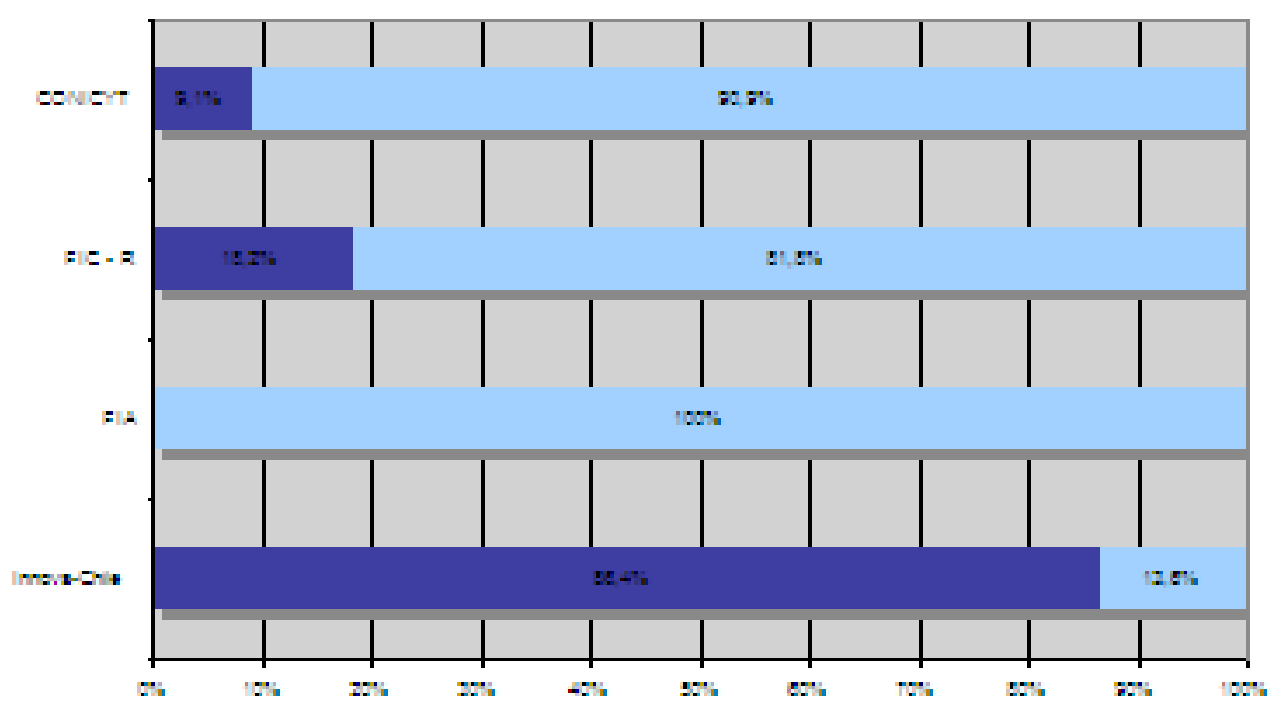

Si No

GRÁFICO 5 Libertad de difusión de la información no confidencial.

Fuente: Elaboración propia 


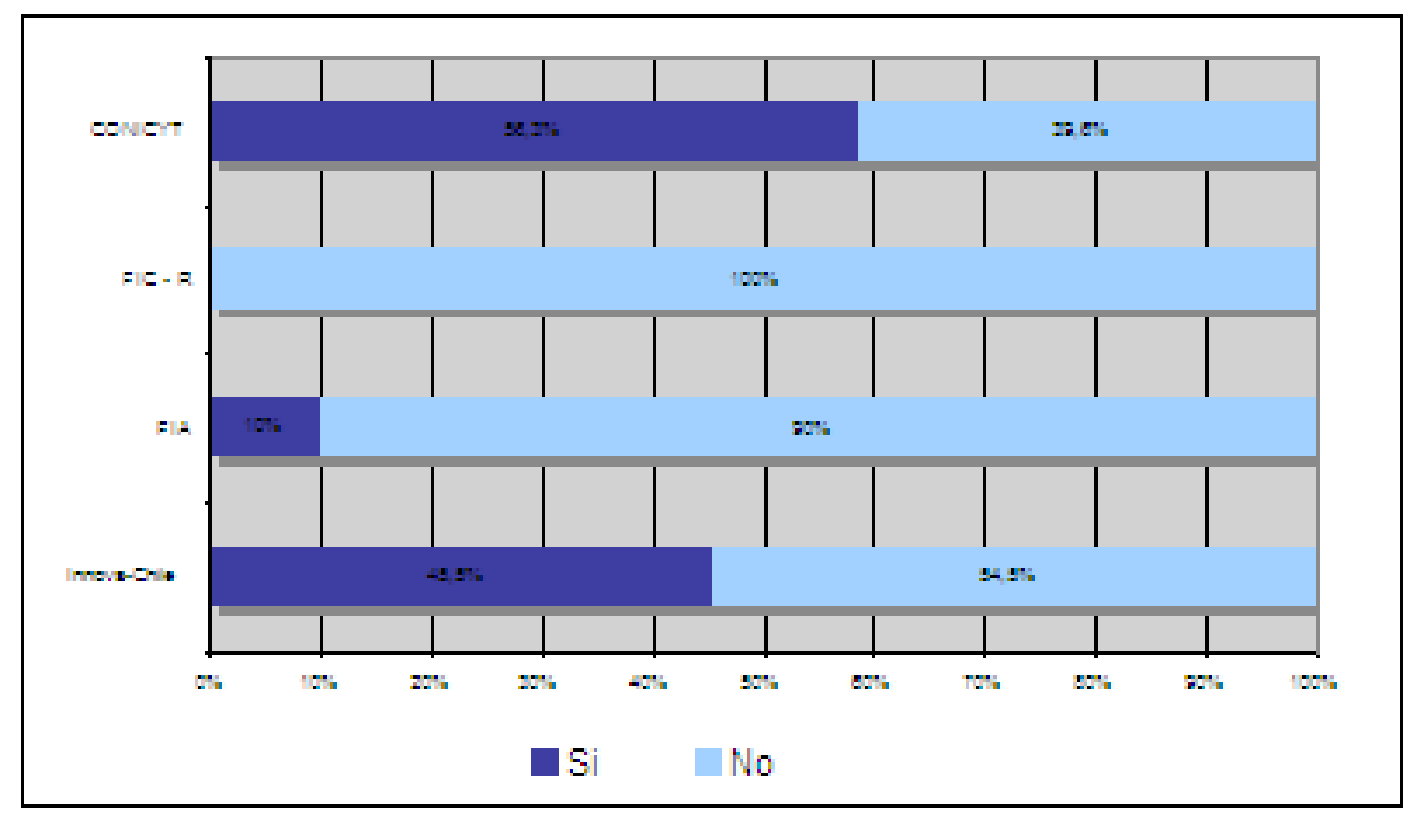

GRÁFICO 6 Definición y planificación de las actividades de difusión

Fuente: Elaboración propia

sabilidad de las actividades de difusión para evitar eventuales situaciones de falta de incentivos post-contractuales.

En relación a la libertad de difusión de la información, se observa que únicamente Innova-Chile resguarda en un porcentaje significativo el derecho a difundir libremente la información no confidencial de los proyectos que se licitan (GRÁFICO 5). El FIC-R se refiere a este aspecto en un $18,2 \%$ de los casos analizados mientras que CONICYT lo hace en un $9,1 \%$. Por su parte, los programas del fondo FIA no resguardan el derecho a difundir libremente la información no confidencial. Consideramos que esta situación debería corregirse para poder aprovechar las externalidades asociadas a la actividad de innovación.

El tercer aspecto evaluado en esta categoría, se refiere a la definición y planificación de las actividades de difusión (GRÁFICO 6). Los programas de CONICYT e Innova-Chile analizados establecen en aproximadamente la mitad de los casos las actividades de difusión a realizar. El FIA se refiere a este aspecto en un $10 \%$ de los casos mientras que en el FIC-R existe un enorme vacío en esta materia, considerando la normativa analizada en esta investigación. Recomendamos que se realice un mayor esfuerzo en la definición y planificación de actividades de difusión en la normativa. Este aspecto es especialmente importante para aquellos fondos que establecen una responsabilidad compartida de las actividades de difusión, es decir, para los fondos Innova-Chile y FIA. De acuerdo con lo señalado anteriormente, el compromiso formal en la licitación funciona como un incentivo al cumplimiento de estas actividades.
4.I.I. Resultados del análisis en materia de difusión de los fondos CONICYT

Si desagregamos los fondos CONICYT por programa, podemos observar que en la mayoría de los casos analizados se define al responsable realizar la actividad de difusión $y$, además, se atribuye esta responsabilidad a la persona o institución beneficiaria del fondo (TABLA 2). En los programas en los que se financian investigaciones de postgrado o informes de especialización es práctica habitual establecer que el investigador deberá publicar los resultados de su trabajo. En otros programas, este aspecto no se aborda suficientemente (FONDECYT) o en absoluto (Cooperación Internacional).

A la pregunta de si existe una cláusula que permita la libre difusión de la información no confidencial, obtenemos unos resultados dispares en cada uno de los programas (TABLA 3). Algunos programas como "EXPLORA" e "Investigación Asociativa" resguardan el derecho de la institución otorgante del fondo a difundir libremente la información no confidencial en el $100 \%$ de los casos analizados. Sin embargo, priman los programas que no contemplan este aspecto.

En relación a la definición y planificación de las actividades, se puede destacar que nuevamente los programas "EXPLORA" e "Investigación Asociativa" acompañados por los programas "Formación de Capital Humano Avanzado" y en menor medida "FONDECYT" cumplen con esta perspectiva. Se requiere un mayor esfuerzo de definición y planifi-

ISSN: 07 I8-2724. (http://www.jotmi.org)

Journal of Technology Management \& Innovation (C) Universidad Alberto Hurtado, Facultad de Economía y Negocios. 
cación en los programas "Astronomía", "FONDE” y "Cooperación Internacional”.

4.I.2. Resultados del análisis en materia de difusión de los fondos FIC-R

En relación a la difusión de la información, los programas del FIC-R se caracterizan por no asignar responsabilidades para llevar a cabo las actividades de difusión, no reservarse formalmente el derecho de difusión de la información y no definir ni planificar las actividades de difusión (TABLA 4). Tan sólo en el programa "Fortalecimiento de Capacidades Científico-Tecnológicas de los Centros Regionales" un $28,6 \%$ de los fondos hacen referencia al derecho a difundir la información no confidencial resultante de la aplicación de los recursos sin restricciones de ningún tipo (TABLA 5). Sin embargo, el porcentaje indica que el interés en la difusión de los resultados, en el programa en su conjunto, es manifiestamente limitado.

4.I.3. Resultados del análisis en materia de difusión de los fondos FIA

En los programas del fondo FIA analizados no hay apenas referencias a las actividades de difusión de la información. Salvo los recursos del programa "Instrumentos complementarios 2008-2009" que atribuyen una responsabilidad compartida a la institución otorgante del fondo y la beneficiaria del mismo para realizar las actividades de difusión, el resto de programas no contemplan nada al respecto (TABLA 6). Esta ausencia se hace todavía más evidente cuando se analiza la información que se refiere a la libre difusión de la información y a la planificación de las actividades (TABLA 7) puesto que tan solo el programa mencionado anteriormente solicita formalmente la realización de actividades de divulgación, estableciendo de esta forma un compromiso exigible a las partes. En otras palabras, salvo los recursos del programa "Instrumentos complementarios 2008-2009" que atribuyen una responsabilidad compartida a la institución otorgante del fondo y a la beneficiaria del mismo para realizar las actividades de difusión, el resto de programas no contemplan nada al respecto (TABLA 7)

4.I.4. Resultados del análisis en materia de difusión de los fondos Innova-Chile

Los fondos analizados del programa Innova-Chile conceden escaso énfasis a las actividades de difusión de la información. En relación a la asignación de responsabilidades de difusión, observamos que, en la mayoría de los casos $(90,9 \%)$, no se hace una mención explícita en el programa al responsable de llevar a cabo la actividad de difusión (TABLA 8).
Sin embargo, en un porcentaje significativo de los fondos, el organismo público se reserva el derecho a difundir libremente la información no confidencial que resultase de la aplicación del programa (TABLA 9). No obstante, la definición y planificación de las actividades de difusión no se comprometen con el otorgamiento del recurso en un porcentaje significativo $(54,5 \%)$.

4.2. Resultados del análisis del esfuerzo en el intercambio de datos

La definición, dentro de la normativa, del soporte y/o formato de los productos resultantes de las actividades seleccionadas en la concesión de los fondos, no presentan resultados homogéneos en los programas evaluados (GRÁFICO 7). Si bien existen programas que en un alto grado hacen solicitud expresa de esta formalidad, existen otros en los cuales la mitad de los fondos analizados no cumplen con este aspecto. De forma concreta, Innova-Chile y CONICYT, con un $95,5 \%$ y un $68,8 \%$ respectivamente, muestran los mejores resultados. Por el contrario, FIA en sólo un $40 \%$ de sus programas analizados hace mención a este requisito, y con el peor resultado se identifica al programa FIC-R, el cual en la totalidad de sus fondos carece de esta solicitud.

La situación anterior es completamente distinta cuando se analizan los programas en los cuales existe una definición explícita de formato o soporte de entrega para los procesos (GRÁFICO 8). Es en este caso donde existe una casi total carencia de normativa al respecto. Los fondos de InnovaChile con un $13,6 \%$ y de FIA con un $10 \%$ de los casos, apenas norman este aspecto. Esta realidad da cuenta del hecho que la mayoría de la información generada durante el desarrollo de las actividades de I+D+i financiadas con recursos públicos permanecen sólo bajo la propiedad de las instituciones beneficiarias. Por tanto, resulta importante analizar si a pesar de que tal práctica es la habitual, de alguna manera la normativa facilita el acceso a la información a otros investigadores.

Dado lo anterior, es necesario considerar que mucha información procedente de estos productos y procesos podría resultar crucial para el desarrollo de actividades adicionales de $++D+i$, llevadas a cabo por otras instituciones. El no contar con dicha información, podría frenar o retrasar dichas actividades innovadoras, o desde otro punto de vista, generar duplicidad en el destino de fondos públicos para el desarrollo de estas. Este hecho da cuenta de la enorme falencia en la normativa frente a las posibilidades de acceso a los resultados generados por las actividades de I+D+i, y a los procesos que posibilitan dichos resultados, para otros investigadores. Al respecto sólo norman el acceso a los productos, de una manera muy residual, los fondos de InnovaChile y CONICYT. Sin embargo, dichos logros no alcanzan a cubrir una quinta parte del total de programas analizados

ISSN: 07 I8-2724. (http://www.jotmi.org)

Journal of Technology Management \& Innovation @ Universidad Alberto Hurtado, Facultad de Economía y Negocios. 


\begin{tabular}{|l|c|c|c|}
\hline \multicolumn{1}{|c|}{ Programa } & QQuién es el responsable de la actividad de difusión? \\
\hline Astronomía & I & B & n.d \\
\hline Cooperación Internacional & $0 \%$ & $100 \%$ & $0 \%$ \\
\hline EXPLORA & $0 \%$ & $0 \%$ & $100 \%$ \\
\hline Investigación Asociativa & $0 \%$ & $100 \%$ & $0 \%$ \\
\hline Atracción/Inserción de Capital Humano Avanzado & $0 \%$ & $100 \%$ & $0 \%$ \\
\hline FONDEF & $0 \%$ & $100 \%$ & $0 \%$ \\
\hline FONDECYT & $0 \%$ & $85,7 \%$ & $14,3 \%$ \\
\hline Formación de Capital Humano Avanzado & $0 \%$ & $66,7 \%$ & $33,3 \%$ \\
\hline
\end{tabular}

TABLA 3 Características de las actividades de difusión de información de los fondos CONICYT por programa Fuente: Elaboración propia

\begin{tabular}{|l|c|c|c|c|c|c|c|c|c|}
\hline & & \multicolumn{7}{|c|}{ Programa } \\
\hline \multicolumn{1}{|c|}{ Cláusulas } & & $(\mathbf{A})$ & $\mathbf{( B )}$ & $\mathbf{( C )}$ & $\mathbf{( D )}$ & $\mathbf{( E )}$ & (F) & (G) & (H) \\
\hline $\begin{array}{l}\text { ¿Existe una cláusula que permita } \\
\text { la libre difusión de información } \\
\text { no confidencial? }\end{array}$ & $\mathrm{Si}$ & $0 \%$ & $0 \%$ & $100 \%$ & $100 \%$ & $0 \%$ & $14,3 \%$ & $0 \%$ & $9,1 \%$ \\
\cline { 2 - 12 } & $\mathrm{No}$ & $100 \%$ & $100 \%$ & $0 \%$ & $0 \%$ & $100 \%$ & $85,7 \%$ & $100 \%$ & $90,9 \%$ \\
\hline $\begin{array}{l}\text { ¿Existe una cláusula que } \\
\text { planifique las actividades de } \\
\text { difusión? }\end{array}$ & $\mathrm{Si}$ & $0 \%$ & $35,3 \%$ & $100 \%$ & $100 \%$ & $100 \%$ & $14,3 \%$ & $66,7 \%$ & $100 \%$ \\
\cline { 2 - 13 } & $\mathrm{No}$ & $100 \%$ & $64,7 \%$ & $0 \%$ & $0 \%$ & $0 \%$ & $85,7 \%$ & $33,4 \%$ & $0 \%$ \\
\hline
\end{tabular}

TABLA 4 Responsabilidad de las actividades de difusión de información de los fondos FIC-R por programa. Fuente: Elaboración propia

\begin{tabular}{|c|c|c|c|}
\hline \multirow[b]{2}{*}{ Programa } & \multicolumn{3}{|c|}{$\begin{array}{l}\text { ¿Quién es el responsable de la actividad } \\
\text { de difusión? }\end{array}$} \\
\hline & I & B & n.d \\
\hline Creación de Unidades Regionales & $0 \%$ & $0 \%$ & $100 \%$ \\
\hline Fortalecimiento de Capacidades Científico-Tecnológicas de los Centros Regionales & $0 \%$ & $0 \%$ & $100 \%$ \\
\hline
\end{tabular}

TABLA 5 Características de las actividades de difusión de información de los fondos FIC-R por programa Fuente: Elaboración propia

\begin{tabular}{|l|c|c|c|}
\hline \multicolumn{1}{|c|}{ Cláusulas } & & \multicolumn{2}{|c|}{ Programa } \\
\hline & & $\begin{array}{c}\text { Creación de Unidades Regio- } \\
\text { nales }\end{array}$ & $\begin{array}{c}\text { Fortalecimiento de Capacidades } \\
\text { Científico-Tecnológicas de los Cen- } \\
\text { tros Regionales }\end{array}$ \\
\hline $\begin{array}{l}\text { ¿Existe una cláusula que permita } \\
\text { la libre difusión de información no } \\
\text { confidencial? }\end{array}$ & $\mathrm{Si}$ & $0 \%$ & $28,6 \%$ \\
\cline { 2 - 4 } $\begin{array}{l}\text { ¿Existe una cláusula que } \\
\text { planifique las actividades de } \\
\text { difusión? }\end{array}$ & $\mathrm{No}$ & $100 \%$ & $71,4 \%$ \\
\cline { 2 - 4 } & $\mathrm{Si}$ & $0 \%$ & $0 \%$ \\
\hline
\end{tabular}

TABLA 6 Responsabilidad de las actividades de difusión de información de los fondos FIA por programa Nota: (I): Institución otorgante del fondo; (B): Beneficiaria del fondo; (N/d): No disponible Fuente: Elaboración propia

ISSN: 07 I8-2724. (http://www.jotmi.org)

Journal of Technology Management \& Innovation (c) Universidad Alberto Hurtado, Facultad de Economía y Negocios. 


\begin{tabular}{|l|c|c|c|}
\hline \multicolumn{1}{|c|}{ Programa } & \multicolumn{2}{|c|}{ ¿Quién es el responsable de la actividad } \\
& \multicolumn{1}{|c|}{ de difusión? }
\end{tabular}

TABLA 6

\begin{tabular}{|l|c|c|c|c|c|c|}
\hline \multicolumn{1}{|c|}{ Cláusulas } & & \multicolumn{5}{c|}{ Programa } \\
\hline \multicolumn{1}{|c|}{} & & (A) & (B) & (C) & (D) & (E) \\
\hline \multirow{2}{*}{$\begin{array}{l}\text { ¿Existe una cláusula que permita la libre difusión de } \\
\text { información no confidencial? }\end{array}$} & $\mathrm{Si}$ & $0 \%$ & $0 \%$ & $0 \%$ & $0 \%$ & $0 \%$ \\
\cline { 2 - 8 } & $\mathrm{No}$ & $100 \%$ & $100 \%$ & $100 \%$ & $100 \%$ & $100 \%$ \\
\hline $\begin{array}{l}\text { ¿Existe una cláusula que planifique las actividades } \\
\text { de difusión? }\end{array}$ & $\mathrm{Si}$ & $0 \%$ & $0 \%$ & $0 \%$ & $100 \%$ & $0 \%$ \\
\cline { 2 - 8 } & $\mathrm{No}$ & $100 \%$ & $100 \%$ & $100 \%$ & $0 \%$ & $100 \%$ \\
\hline
\end{tabular}

TABLA 7 Características de las actividades de difusión de información de los fondos FIA por programa.

Nota: (A) Convocatoria Programa Tecnológico para la Agroindustria Hortofrutícola, la Industria Vitivinícola y la Industria de la Carne Bovina y Ovina 2009; (B) Convocatoria Proyectos y Estudios de Innovación 2008-2009; (C) Convocatoria Programas de Innovación Territorial por rubros o cadenas productivas 2008-2009; (D) Convocatoria Instrumentos complementarios 2008-2009; (E) Convocatorias especiales 2008-2009. Fuente: Elaboración propia.

\begin{tabular}{|l|c|c|c|}
\hline & \multicolumn{3}{|c|}{ ¿Quién es el responsable de la actividad de difusión? } \\
\hline Programa & I & B & n.d \\
\hline Innova-Chile & \multicolumn{2}{|c|}{$9,1 \%$} & $90,9 \%$ \\
\hline
\end{tabular}

TABLA 8 Responsabilidad de las actividades de difusión de información de los fondos CORFO por programa Fuente: Elaboración propia

\begin{tabular}{|l|c|c|}
\hline \multicolumn{1}{|c|}{ Cláusulas } & Programa \\
\hline \multirow{2}{*}{ ¿Existe una cláusula que permita la libre difusión de información no confidencial? } & Innova-Chile \\
\cline { 2 - 3 } ¿Existe una cláusula que planifique las actividades de difusión? & No & $86,4 \%$ \\
\cline { 2 - 3 } & $\mathrm{Si}$ & $13,6 \%$ \\
\hline
\end{tabular}

TABLA 9 Características de las actividades de difusión de información de los fondos CORFO por programa Fuente: Elaboración propia

ISSN: 07 I8-2724. (http://www.jotmi.org)

Journal of Technology Management \& Innovation (c) Universidad Alberto Hurtado, Facultad de Economía y Negocios. 


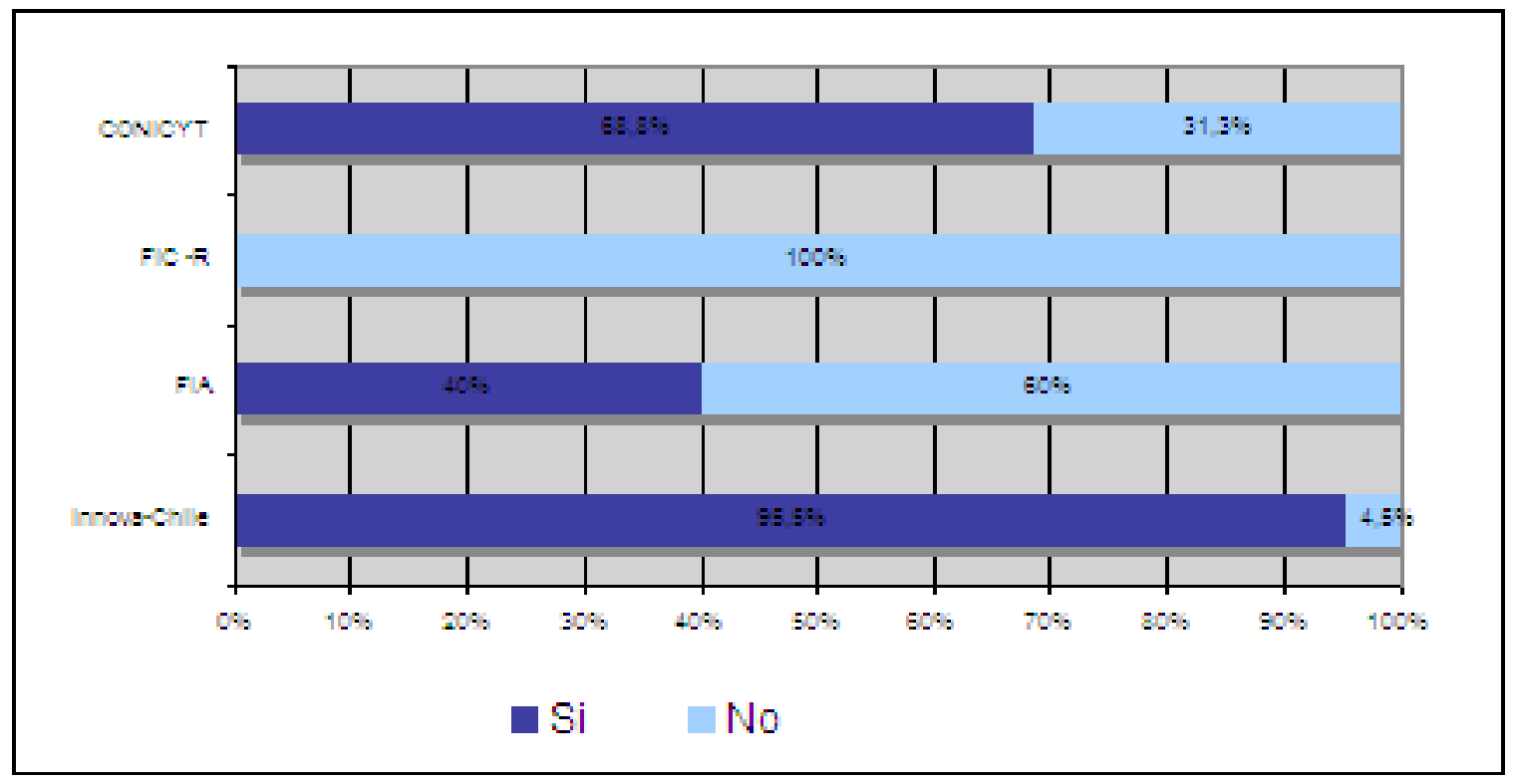

GRÁFICO 7 Definición del soporte/formato de entrega de los productos.

Fuente: Elaboración propia.

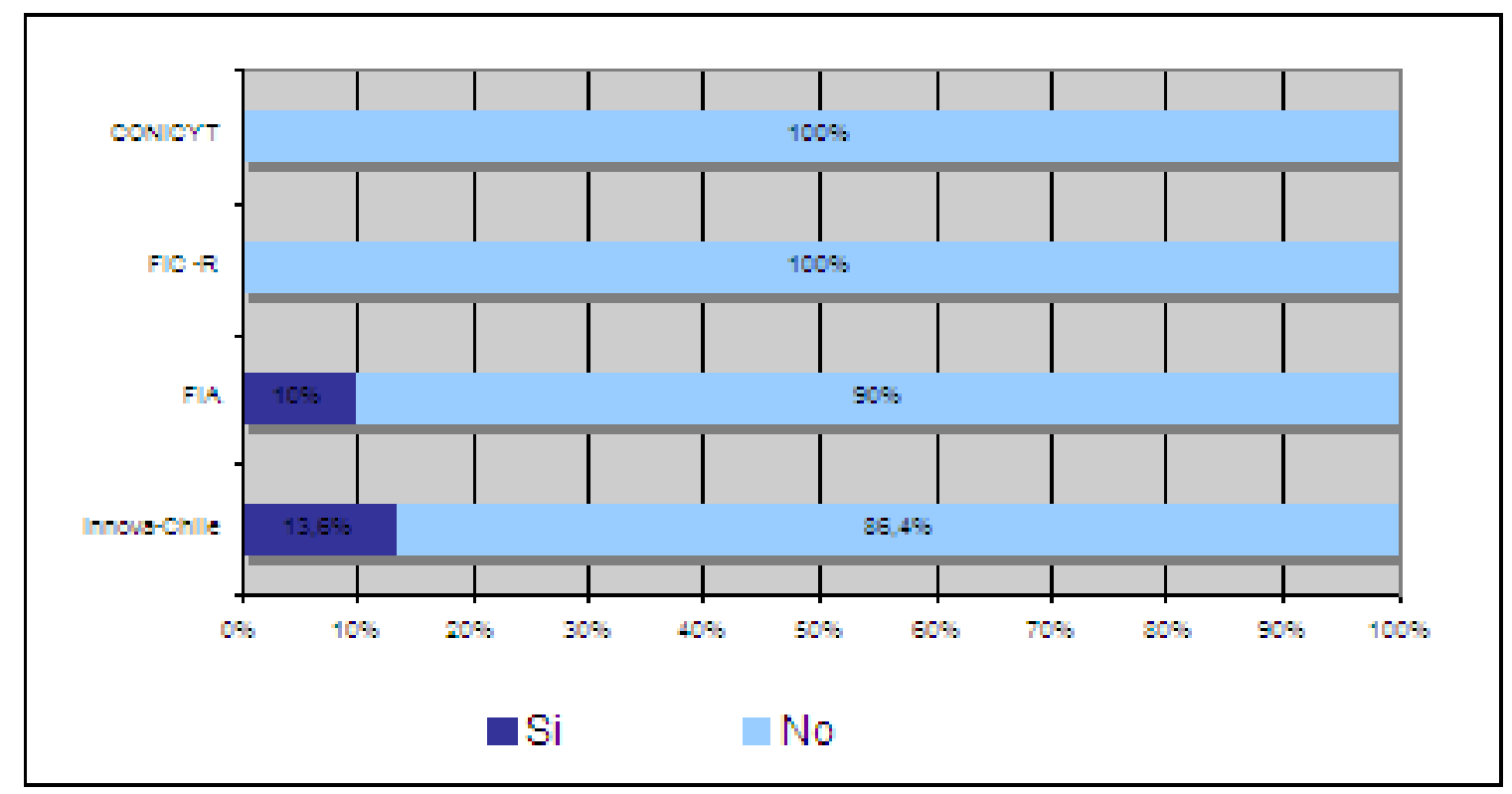

GRÁFICO 8 Definición del soporte/formato de entrega de los procesos Fuente: Elaboración propia. 
en cada fondo (GRÁFICO 9). Innova-Chile resulta ser, adicionalmente, el único programa que establece algún tipo de norma que permite el acceso a otros investigadores a los procesos resultantes de cada fondo (GRÁFICO I0). Sin embargo, los resultados obtenidos (I3,6\%) comparten con los que se refieren al producto el escaso énfasis puesto en este aspecto.

Tal carencia da cuenta de una preocupante realidad que debiese ser normada de acuerdo a lo que las tendencias científicas internacionales actualmente sugieren $y$, que a pesar de ser minoritarias e incipientes, se reconoce en ellas un papel clave para el fortalecimiento de las actividades innovadoras en diversas áreas.

Finalmente, resulta relevante evaluar lo que la normativa establece en términos del cumplimiento de los compromisos contractuales por parte de la institución beneficiaria de los fondos (GRÁFICO II). Si de alguna manera este aspecto es normado mediante incentivos/descincentivos, ello podría garantizar, en primer lugar, el buen uso y aprovechamiento de los fondos públicos, y en segundo lugar, la entrega de los productos y procesos de las actividades financiadas en los plazos respectivos y bajo las características y condiciones solicitadas.

Concretamente, en nuestro análisis sólo uno de los cuatro fondos (FIC-R) no contempla en absoluto dicho aspecto. Por su parte, FIA y CONICYT lo norman en un alto grado, con presencia en más del $40 \%$ y $50 \%$ de los programas estudiados, respectivamente. Finalmente, resaltan notoriamente las buenas prácticas que en este sentido aplica Innova-Chile, programa dentro del cual la mayoría de las bases de las convocatorias analizadas $(90,9 \%)$ establece algún tipo de normativa al respecto.

Por tanto, de forma general, a pesar de la existencia en un elevado porcentaje de fondos de una normativa que incentive el cumplimiento de los compromisos contraídos, aun hay carencias al respecto, las cuales deberían ser subsanadas para garantizar el buen uso del financiamiento público en las actividades de innovación y la posibilidad de acceso a los resultados, tanto en productos como en procesos.

\section{Conclusiones y recomendaciones}

Para el primer aspecto evaluado, difusión de la información, los resultados indican que la mayoría de los fondos públicos del Sistema Nacional de Innovación no definen quién es el responsable de llevar a cabo las actividades de difusión. Únicamente destaca CONICYT por definir, en su caso, a la beneficiaria como responsable de esta actividad. El resto de fondos presentan una fuerte carencia en este aspecto, evidenciándose manifiestamente en los fondos FIC-R en los que no se contempla nada al respecto. Para los fondos Innova-Chile y FIA, dada la responsabilidad compartida que se establece en algunos de sus programas y la escasa definición y planificación de las actividades de difusión, recomendamos asignar de manera clara a cada agente las actividades de difusión de la información y definir quién tiene la responsabilidad sobre esas actividades para evitar eventuales situaciones de falta de incentivos post-contractuales. En relación a la libertad de difusión de la información, se observa que únicamente Innova-Chile resguarda en un porcentaje significativo el derecho a difundir libremente la información no confidencial de los proyectos que se licitan. Esta carencia en el resto de fondos públicos podría estar generando un desaprovechamiento de los potenciales beneficios externos del proceso innovador. Consideramos que debería realizarse un mayor esfuerzo para solucionar este vacío en la normativa. Finalmente, en lo que se refiere a la definición y planificación de las actividades de difusión, los resultados del análisis indican que esta es una tarea pendiente para todos los fondos, pero especialmente para el FIC-R y el FIA. Recomendamos que se definan y planifiquen las actividades de difusión en la normativa para poder exigir su cumplimiento a los responsables de realizarlas.

En el segundo aspecto evaluado, los esfuerzos en el intercambio de datos, los principales resultados del estudio dan cuenta de una importante carencia de requisitos o incentivos para hacer entrega de los resultados de las actividades desarrolladas en algún soporte o formato concreto, $y$ en las posibilidades o condiciones de acceso a dichos resultados para otros investigadores. Lo anterior se intensifica aun más cuando el análisis sólo se lleva a cabo para los resultados de los procesos de las actividades desarrolladas, lo cual es señal de un gran vacío en el desarrollo de estas prácticas que, a pesar de constituir una experiencia nueva y minoritaria, manifiesta una necesidad real en el ámbito científico. Disponer de información procedente de estos productos y procesos, en los plazos y condiciones requeridos, podría resultar crucial para el desarrollo de actividades adicionales de I+D+i llevadas a cabo por otros agentes. Dicha información ayudaría a fortalecer las actividades innovadoras en diversas áreas, por el contrario, no contar con ella podría obstaculizarlas, e inclusive generar duplicidad en el destino de fondos públicos para su desarrollo. Dado lo anterior, consideramos necesario subsanar esta falencia dentro de las bases que regulan la postulación para la obtención de fondos públicos, y evaluar cuidadosamente las tipologías de programas y la información resultante de cada uno de ellos, de forma tal de resguardar apropiadamente aquella información que, dada su naturaleza, podría ser de tipo confidencial, o en la cual el sólo hecho de disponer de ella públicamente podría generar perjuicios. Por otra parte, en referencia al cumplimiento de los compromisos contraídos por el beneficiario de los fondos, sólo uno de los cuatro (FIC-R) no contempla en absoluto dicho as- 


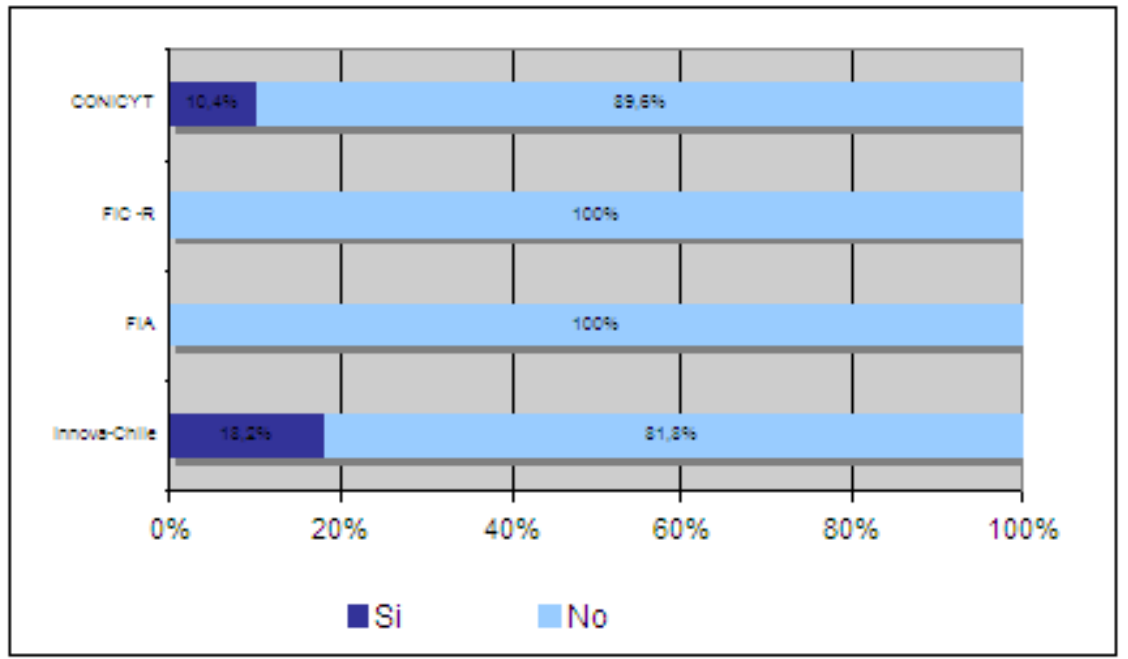

GRÁFICO 9 Libertad de acceso a los productos para otros investigadores. Fuente: Elaboración propia.

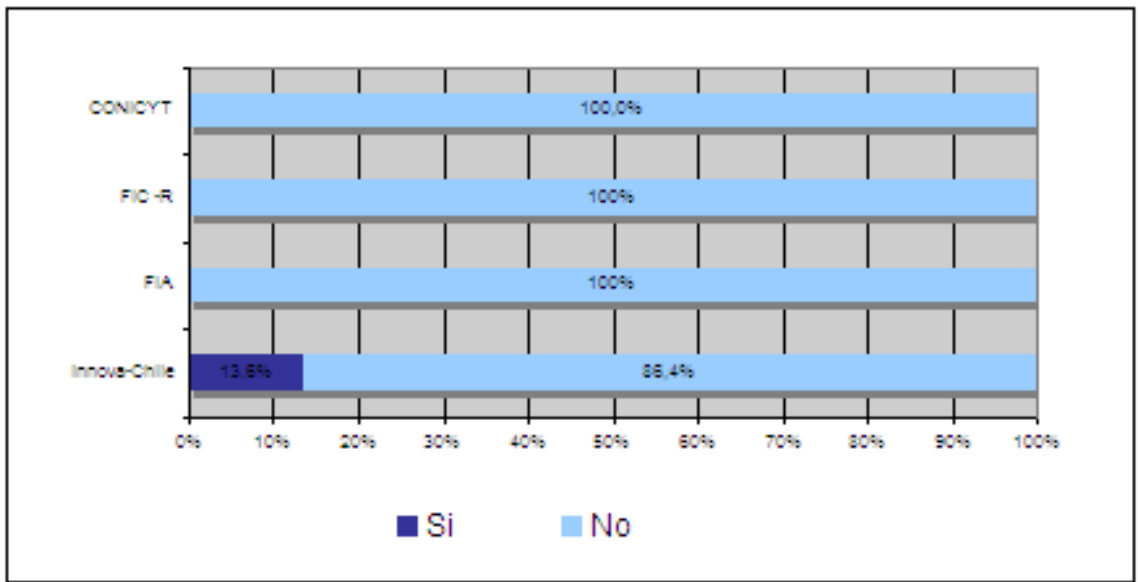

GRÁFICO 10 Libertad de acceso a los procesos para otros investigadores. Fuente: Elaboración propia.

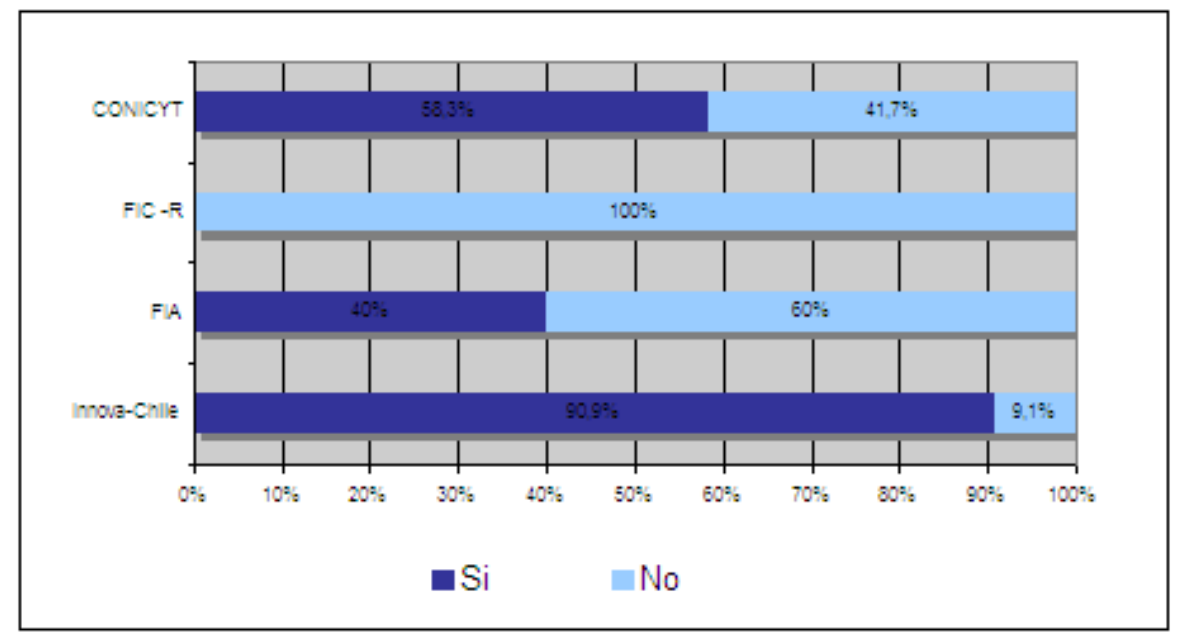

GRÁFICO I I Incentivos al cumplimiento de compromisos contractuales. Fuente: Elaboración propia. 
pecto, resaltando notoriamente las buenas prácticas que en este sentido aplica Innova-Chile, programa dentro del cual la mayoría de las bases de las convocatorias analizadas $(90,9 \%)$ establecen algún tipo de normativa al respecto. Sin embargo, de manera general, aun hay carencias, las cuales deberían ser subsanadas para garantizar el buen uso del financiamiento público en las actividades de innovación, y la posibilidad de acceso a los resultados por parte de científicos e investigadores. Por tanto, y de forma general, la definición dentro de la normativa, del soporte y/o formato de los productos y procesos resultantes de las actividades seleccionadas en la concesión de los fondos presenta un espacio para la mejora de resultados. Por su parte, el establecimiento de las condiciones de acceso a la información a otros investigadores muestra serias carencias, mientras que los incentivos al cumplimiento de los compromisos contraídos, a pesar de mostrar mejores resultados, deberían presentar un mayor esfuerzo normativo.

\section{Bibliografía}

ABOWD, J., Lane, J. (2004). New approaches to confidentiality protection: synthetic data, remote access and research data centers privacy in statistical databases. En: DomingoFerrer, J., Torra, V. (Eds.), Privacy in Statistical Databases. Springer-Verlag, Berlín. pp.282-289.

BACHRACH, C., Spittel, M. (20II). Developing a plan for data sharing. En: Stover, E., Anne Boyce, C. (Eds.), How to write a successful research grant application. Springer, EE.UU. pp. 369-374.

DEN BESTEN, M., David, P., Schroeder, R. (2010). Research in e-science and open access to data and information. En: Hunsinger, J., Klastrup, L.,Allen, M. (Eds.), International Handbook of Internet Research. Springer, EE.UU. pp. 65-96.

EITO, R. (2007). Normalización documental y colaboración electrónica: una visión retrospectiva. Revista Española de Documentación Científica, 30(I), 24-48.

HERNÁNDEZ, R., Fernández, C. Baptista, P. (2008). Metodología de la investigación. McGraw Hill Interamericana, México.

IDER (20I0). Estado del arte nacional e internacional sobre manejo y políticas de acceso a datos de investigación e información científica y tecnológica financiada con fondos públicos y recomendaciones de buena prácticas. CONICYT, Santiago de Chile.

NATURE (2009). Data's shameful neglect. Nature, 46 I (726I), 145.
NELSON, B. (2009). Empty archives. Nature, 46 I (726I), I60163.

PILAT, D., Fukasaku, Y. (2007). OECD principles and guidelines for access to research data from public funding. Data Science Journal, 6(I7), 4-II.

RAMOS, L.F., Mendo, C., Arquero, R. (2009). La producción informativa y documental del Estado: hacia un inventario de los recursos públicos. Revista Española de Documentación Científica, 32(I), 40-59.

RODRÍGUEZ,A. (2008). Elementos que fundamentan el acceso abierto. Investigación Bibliotecológica, 22(44), 161-182.

SABOURIN, M., Dumouchel, B. (2007). Canadian national consultation on access to scientific research data. Data Science Journal, 6(I7), 26-35.

SCHMAL, R., Acuña, D., Klein, P. (20I I). Una plataforma web para gestionar los derechos de propiedad intelectual resultantes de la investigación universitaria. Journal of Technology Management \& Innovation, 6(4), 258-275.

SAN JOSÉ MONTANO, B. (2009). Acceso abierto (open access): un modelo necesario de comunicación científica. Pediatría Atención Primaria, I I (42), 299-3 I I.

SCHRÖDER, P. (2007). Possible downsides to data sharing in the research commons: assets and liabilities, opportunities and risks. Data Science Journal, 6(I7), 67-70.

UHLIR, P., Schröder, P. (2007). Open data for a global science. Data Science Journal, 6(I7), 36-53.

VÁZQUEZ BARQUERO, A. (2005). Las nuevas fuerzas del desarrollo.Antoni Bosch, Barcelona.

VÁZQUEZ BARQUERO, A. (1999). Desarrollo, redes e innovación. Lecciones sobre desarrollo endógeno. Pirámide, Madrid.

XU, G. (2007). Open access to scientific data: promoting science and innovation. Data Science Journal, 6(17), 2I-25. 